\title{
Papers
}

\section{Exercise training meta-analysis of trials in patients with chronic heart failure (ExTraMATCH)}

\author{
ExTraMATCH Collaborative
}

\begin{abstract}
Objective To determine the effect of exercise training on survival in patients with heart failure due to left ventricular systolic dysfunction.

Design Collaborative meta-analysis.

Inclusion criteria Randomised parallel group controlled trials of exercise training for at least eight weeks with individual patient data on survival for at least three months.

Studies reviewed Nine datasets, totalling 801 patients: 395 received exercise training and 406 were controls.

Main outcome measure Death from all causes.

Results During a mean (SD) follow up of 705 (729) days there were $88(22 \%)$ deaths in the exercise arm and 105 (26\%) in the control arm. Exercise training significantly reduced mortality (hazard ratio $0.65,95 \%$ confidence interval, 0.46 to $0.92 ; \log$ $\left.\operatorname{rank} \chi^{2}=5.9 ; \mathrm{P}=0.015\right)$. The secondary end point of death or admission to hospital was also reduced $(0.72,0.56$ to 0.93 ; $\log$ $\left.\operatorname{rank} \chi^{2}=6.4 ; \mathrm{P}=0.011\right)$. No statistically significant subgroup specific treatment effect was observed.

Conclusion Meta-analysis of randomised trials to date gives no evidence that properly supervised medical training

programmes for patients with heart failure might be dangerous, and indeed there is clear evidence of an overall reduction in mortality. Further research should focus on optimising exercise programmes and identifying appropriate patient groups to target.
\end{abstract}

\section{Introduction}

Exercise training is known to reduce the debilitating symptoms of chronic heart failure, such as breathlessness and fatigue, through effects on the cardiovascular and musculoskeletal systems. ${ }^{1-3}$ Despite this, it is not widely utilised, perhaps because data on its effect on survival are limited. ${ }^{4}$

Randomised controlled trials have focused largely on symptomatic benefits and on surrogate markers of prognosis, including neurohormonal balance, variability in heart rate, and peak oxygen consumption. ${ }^{1}$ Individual trials have mostly been small. Meta-analyses of randomised trials can provide more reliable estimates of treatment effect than individual trials because they have greater statistical power. When based on data from individual patients they have several important advantages over those based solely on published data. ${ }^{5}$

We report a collaborative meta-analysis, based on individual patient data, of randomised controlled trials comparing exercise training with usual care in patients with chronic heart failure due to left ventricular systolic dysfunction. We aimed to obtain reliable and precise estimates of overall treatment benefit on death and on the secondary end point of death or admission to hospital.

\section{Methods}

A collaborative group was established, coordinated from the Heart Failure Unit of the Imperial College School of Medicine, London. A prospective protocol was written and agreed by the collaborative group before data collection, specifying the methods to be used, the main prespecified analyses, and a common dataset of collected variables.

We searched Medline for randomised controlled trials since 1990 of exercise training in patients with chronic congestive heart failure or left ventricular dysfunction. We cross checked our findings to identify any other published or unpublished trials by consulting researchers and colleagues in exercise physiology and heart failure and by scrutinising reference lists from review articles, and abstracts presented at scientific sessions and published in Circulation, the Journal of the American College of Cardiology, and the European Heart Journal. A subsequent search of the Cochrane Reviews database yielded no additional studies.

\section{Selection and validity assessment}

The characteristics of trials to be included were that they should be randomised parallel group controlled trials and should evaluate exercise training without any other simultaneous intervention that could confound the results, should study patients with stable heart failure (three months or more of stability) due to left systolic ventricular dysfunction (left ventricular ejection fraction less than 50\%), should have an exercise programme lasting eight weeks or more, should utilise training involving at least both legs (trials of arm or single leg training were excluded), and should have survival follow up of three months or more.

\section{Data abstraction and study characteristics}

Initial screening identified 101 potential reports. Several groups had reported information from the same trial in more than one publication or had conducted more than one similar trial. Individual patients were therefore combined into one dataset for that centre, yielding 41 non-overlapping datasets: 27 had been published as peer reviewed original articles, 12 had been presented in abstract form only, and two had not been published in either form. Nine met the eligibility criteria.

After formal agreement, all principal investigators were asked to provide datasets in the form of anonymised individual patient data for each patient originally randomised. Datasets included age, sex, blood pressure, ischaemic versus nonischaemic causes, functional class according to the New York Heart Association, left ventricular ejection fraction, exercise peak 
oxygen consumption, dates of randomisation, follow up, death, and, if available, data on any events that had occurred during hospital stay. If patients experienced more than one such event, only the first was recorded. Data on drugs and renal function were requested, but non-availability of this data was not an exclusion criterion for the meta-analysis.

Datasets from each trial were transferred in electronic format (email or disk) to the coordinating centre at the Heart Failure Unit. They were checked for completeness and consistency to ensure that no errors had occurred in reformatting of the data and to check for consistency with the original publications. Queries were resolved by communication with the principal investigators. The number of events in this meta-analysis may differ slightly from those reported by the trials because follow up is now more complete. The datasets were then incorporated into the master database, which was used for analysis. Results of analyses were discussed at several meetings.

\section{Analysis of potential publication bias}

The potential for publication bias was first examined visually by constructing a funnel plot displaying precision of the estimate of the effect size (the reciprocal of its standard error) against the estimate of the effect size (odds ratio, on a logarithmic scale). ${ }^{6}$ Asymmetry was assessed formally by the Egger test. ${ }^{7}$ Finally, the association between variance and effect size was analysed by rank correlation using the Kendall tau method.

\section{Analysis of time to end point}

The prespecified event information collected was time to death (from any cause) and, in those studies that recorded it, time to first admission to hospital (for any reason). In all cases an intention to treat approach was used, so events occurring after allocation of treatment were included regardless of the duration of participation in an exercise programme. We considered a $\mathrm{P}$ value of less than 0.05 as significant.

The primary end point was time to death. A secondary end point was death or time to admission to hospital. Time to death was available for all studies and time to death or admission to hospital was available for eight of the nine studies. The treatment arms were combined into one arm as were the placebo arms. Statistical packages used were SAS Statview 5.0 and R (R Foundation for Statistical Computing, www.r-project.org). The Kaplan-Meier method was applied to display the time to end point in the exercise and control arms during two years of follow up. After testing the Cox proportional hazards assumption, we calculated the hazard ratio for events in the exercise group compared with the non-exercise group. ${ }^{8}$ Statistical significance was tested with the Mantel-Cox log rank method.

\section{Subgroup meta-analysis of dichotomous end points}

The effect of exercise was also assessed in prespecified subgroups-males versus females, New York Heart Association functional class I-II versus III-IV, ischaemic versus non-ischaemic causes, age, peak oxygen uptake $(<15 \mathrm{ml} / \mathrm{kg} / \mathrm{min} v \geq 15 \mathrm{ml} / \mathrm{kg} /$ $\mathrm{min})$, left ventricular ejection fraction $(<27 \% v \geq 27 \%)$, and duration of training programme ( $<28$ weeks $v$ at least 28 weeks). The continuous variables were each dichotomised at their corresponding median values over the whole dataset. For each subgroup we determined whether the interaction term (subgroup $\times$ treatment arm) was significantly different from zero.

\section{Results}

Nine prospective studies met the criteria for the meta-analysis (fig 1). Of these, eight were conducted in Europe. ${ }^{9-16}$ The number

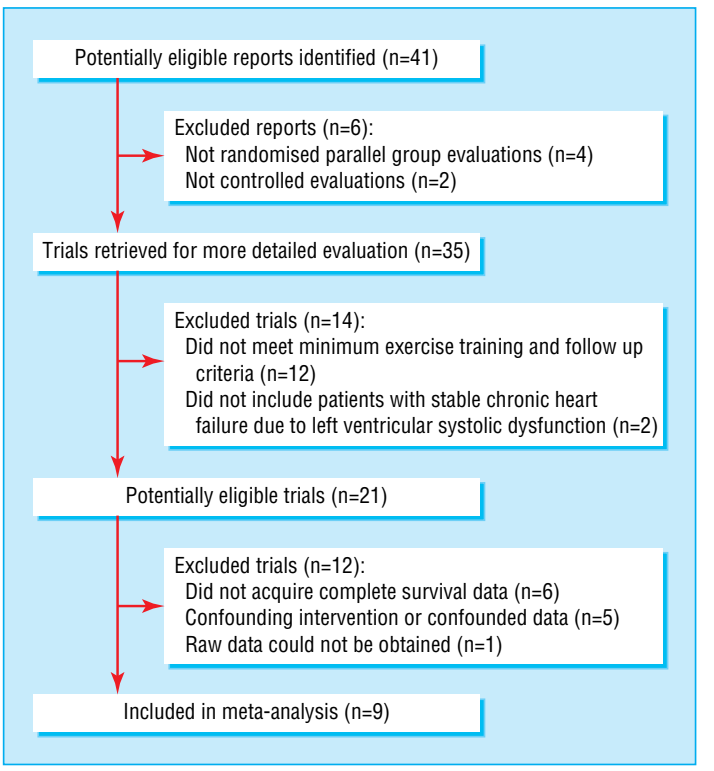

Fig 1 Selection process for studies included in meta-analysis

of patients ranged from 27 to $181 .^{213}$ The duration of the training programme ranged from eight weeks in a small trial (50 patients) to a year or more in the largest studies. ${ }^{2491014}$ Mean follow up was from 159 to 2284 days (table 1). One dataset had no date of admission to hospital and therefore could not be included in the Kaplan-Meier analysis for that variable. ${ }^{15}$ A total of 801 patients with evidence of left ventricular dysfunction and clinical heart failure were randomly assigned to an exercise training programme $(n=395)$ or to the control group $(n=406$; table 2).

\section{Analysis of publication bias}

We found no evidence of publication bias (fig 2). The intercept of the regression relation effect between effect size (standard error) and $1 /$ standard error was not significantly different from zero, neither for death (intercept $=0.52, \mathrm{P}=0.58$ ) nor for the combined end point of death or admission to hospital (intercept $=-0.04, \quad \mathrm{P}=0.97$ ). The Kendall tau correlation coefficient between log of odds ratio and its standard error across the nine studies was 0.0 for mortality analysis, 0.25 for analysis of admission to hospital, and -0.06 for the combined end points of death or admission to hospital ( $\mathrm{P}>0.5$ for all). The funnel plots for each end point showed no significant variation in the log odds ratio with precision of the estimate.

\section{Effect of training on outcomes}

\section{Primary end point of mortality}

Overall, there were 88 deaths in the exercise arm (median time to event, 618 days) and 105 in the control arm (421 days). Mortality was significantly lower in the exercise group $\left(\log\right.$ rank $\chi^{2}=5.9$, $\mathrm{P}=0.015$ ). After verification of the Cox proportional hazards assumption $\left(\chi^{2}=3.1, \mathrm{P}>0.05\right)$, the hazard ratio for mortality was computed to be 0.65 (95\% confidence interval 0.46 to 0.92 ). The survival curves are shown in figure 3 . These results would imply a number needed to treat of 17 to prevent one death in two years.

\section{Secondary end point of death or admission to hospital}

The secondary end point of death or admission to hospital occurred in 127 patients in the exercise arm and 173 in the control arm. Data on time to death or admission to hospital was available for eight datasets. The median time to admission to 


\begin{tabular}{|c|c|c|c|c|c|c|}
\hline Study & Location & $\begin{array}{l}\text { No in groups } \\
\text { (training, control) }\end{array}$ & $\begin{array}{l}\text { Duration of } \\
\text { training } \\
\text { programme (days) }\end{array}$ & $\begin{array}{l}\text { Mean (SD) duration } \\
\text { of follow up (days) }\end{array}$ & $\begin{array}{l}\text { Description of training } \\
\text { programme }\end{array}$ & Intensity of programme \\
\hline Belardinelli et al, $1999^{4}$ & Italy & 50,49 & 420 & $1144(461)$ & $\begin{array}{l}\text { Supervised cycling, } 60 \text { minutes } \\
\text { three days a week for eight } \\
\text { weeks, then two days a week }\end{array}$ & $60 \%$ peak oxygen consumption \\
\hline Dubach et al $1997^{910}$ & Switzerland & 24,26 & 56 & $261(106)$ & $\begin{array}{l}\text { Supervised walking, two hours } \\
\text { daily; supervised cycling } 40 \\
\text { minutes four days a week }\end{array}$ & $80 \%$ peak oxygen consumption \\
\hline Giannuzzi et al, $1997^{11}$ & Italy & 46,42 & 168 & $206(35)$ & $\begin{array}{l}\text { Supervised cycling, } 30 \text { minutes } \\
\text { three days a week for two } \\
\text { months, then home based } 30 \\
\text { minutes for three days a week } \\
\text { and walking for } 30 \text { minutes }\end{array}$ & $80 \%$ peak heart rate \\
\hline Hambrecht et al, $1995^{12}$ & Germany & 34,35 & 168 & $159(22)$ & $\begin{array}{l}\text { Supervised and home based } \\
\text { walking, calisthenics, cycling } \\
40-60 \text { minutes a day }\end{array}$ & $70 \%$ peak oxygen consumption \\
\hline Kiilavuori et al, $2000^{13}$ & Finland & 12,15 & 182 & $2284(1213)$ & $\begin{array}{l}\text { Supervised cycling } 30 \text { minutes } \\
\text { three days a week for three } \\
\text { months, then home based } \\
\text { training (walking, cycling, } \\
\text { rowing, and swimming) }\end{array}$ & $\begin{array}{l}50-60 \% \text { peak oxygen } \\
\text { consumption }\end{array}$ \\
\hline McKelvie et al, $2002^{2}$ & Canada & 90,91 & 364 & $557(219)$ & $\begin{array}{l}\text { Supervised aerobic (cycling, } \\
\text { treadmill, arm) and resistance } \\
\text { training } 30 \text { minutes three days } \\
\text { a week for three months, then } \\
\text { home based aerobic training } \\
\text { three days a week }\end{array}$ & $60-70 \%$ peak heart rate \\
\hline Zanelli et al, $1997^{14}$ & Italy & 76,79 & 364 & $304(140)$ & $\begin{array}{l}\text { Supervised aerobic (cycling, } \\
\text { treadmill, arm) and resistance } \\
\text { training } 30 \text { minutes two days a } \\
\text { week and home based cycling } \\
\text { three days a week for two } \\
\text { months, then only home based } \\
\text { aerobic training five days a } \\
\text { week }\end{array}$ & $70 \%$ peak oxygen consumption \\
\hline Wielenga et al, $1999^{15}$ & Netherlands & 41,39 & 84 & $1440(917)$ & $\begin{array}{l}\text { Supervised cycling, walking, } \\
\text { ball game } 30 \text { minutes three } \\
\text { days a week for eight weeks, } \\
\text { then two days a week }\end{array}$ & $60 \%$ peak heart rate \\
\hline Willenheimer et al, $1998^{16}$ & Sweden & 22,30 & 112 & $1623(797)$ & $\begin{array}{l}\text { Supervised interval cycling } \\
\text { training ( } 90 \text { second exercise } \\
\text { and } 30 \text { second rest) for } 15-45 \\
\text { minutes two days a week }\end{array}$ & $\begin{array}{l}80 \% \text { peak oxygen consumption } \\
\text { or grade } 15 \text { Borg scale }\end{array}$ \\
\hline Total & & 395,406 & 213 (135) & 705 (729) & & \\
\hline
\end{tabular}

hospital was 426 days in the exercise arm and 371 days in the control arm. Kaplan-Meier analysis of the secondary end point confirmed a significant benefit in the exercise arm (log rank $\chi^{2}=6.4, \mathrm{P}=0.011$, fig 3 ). The Cox proportional hazards assumption was verified $\left(\chi^{2}=1.5, \mathrm{P}>0.05\right)$, and the hazard ratio for the combined end point was 0.72 ( 0.56 to 0.93 ).

\section{Outcomes stratified by baseline characteristics}

Subgroup analyses for mortality and the combined end point of mortality or admission to hospital are shown in figures 4 and 5, respectively. In some instances one subgroup (for example, the one with ejection fraction <27\%) showed a statistically significant treatment effect whereas the contrary group (for example, the one with ejection fraction $\geq 27 \%$ ) did not. In each subgroup (and for each end point) there was, however, no significant interaction term between treatment allocation and subgroup. No evidence was therefore found of a subgroup specific treatment effect.

\section{Discussion}

Our meta-analysis of randomised controlled trials shows that exercise training significantly improves survival time in patients with chronic heart failure due to left ventricular systolic dysfunction. Time to death or admission to hospital was also significantly extended. Subgroup analysis showed significant interaction
Table 2 Characteristics of patients included in meta-analysis. Values are numbers (percentages) unless indicated otherwise

\begin{tabular}{|c|c|c|}
\hline Characteristics & Training ( $\mathrm{n}=395)$ & Control $(n=406)$ \\
\hline Male & 88.4 & 87.2 \\
\hline Mean (SD) age (years) & $60.5 \quad(9.3)$ & $59.7(13.2)$ \\
\hline Mean (SD) NYHA class & $\begin{array}{ll}2.6 & (0.6)\end{array}$ & $2.5 \quad(0.6)$ \\
\hline Ischaemic heart disease & 59.7 & 58.7 \\
\hline $\begin{array}{l}\text { Mean (SD) left ventricular ejection } \\
\text { fraction }(\%)\end{array}$ & $27.9 \quad(8.3)$ & (8.6) \\
\hline $\begin{array}{l}\text { Mean (SD) peak oxygen uptake } \\
(\mathrm{ml} / \mathrm{kg} / \mathrm{min})\end{array}$ & $15.4 \quad(4.0)$ & $15.2 \quad(3.9)$ \\
\hline \multicolumn{3}{|l|}{$\begin{array}{l}\text { Mean (SD) renal function (laboratory } \\
\text { findings) }^{\star} \text { : }\end{array}$} \\
\hline Serum creatinine $(\mathrm{mg} / \mathrm{dL})$ & $1.4 \quad(0.4)$ & $1.4 \quad(0.5)$ \\
\hline Urea $(\mathrm{mg} / \mathrm{dL})$ & $61.3(40)$ & $63.7(38)$ \\
\hline \multicolumn{3}{|l|}{ Drugst: } \\
\hline $\begin{array}{l}\text { Angiotensin converting enzyme } \\
\text { inhibitors }\end{array}$ & 73.4 & 73.2 \\
\hline Anticoagulant & 40.0 & 36.9 \\
\hline Aspirin & 30.1 & 30.8 \\
\hline Amiodarone & 10.9 & 12.8 \\
\hline$\beta$ adrenergic blockade & 12.2 & 14.5 \\
\hline Digitalis & 50.4 & 47.8 \\
\hline Diuretics & 68.9 & 69.5 \\
\hline Nitrate & 40.0 & 31.0 \\
\hline
\end{tabular}

NYHA=New York Heart Association.

${ }^{*}$ Renal function known for 146 patients.

†Drugs known for 655 patients. 

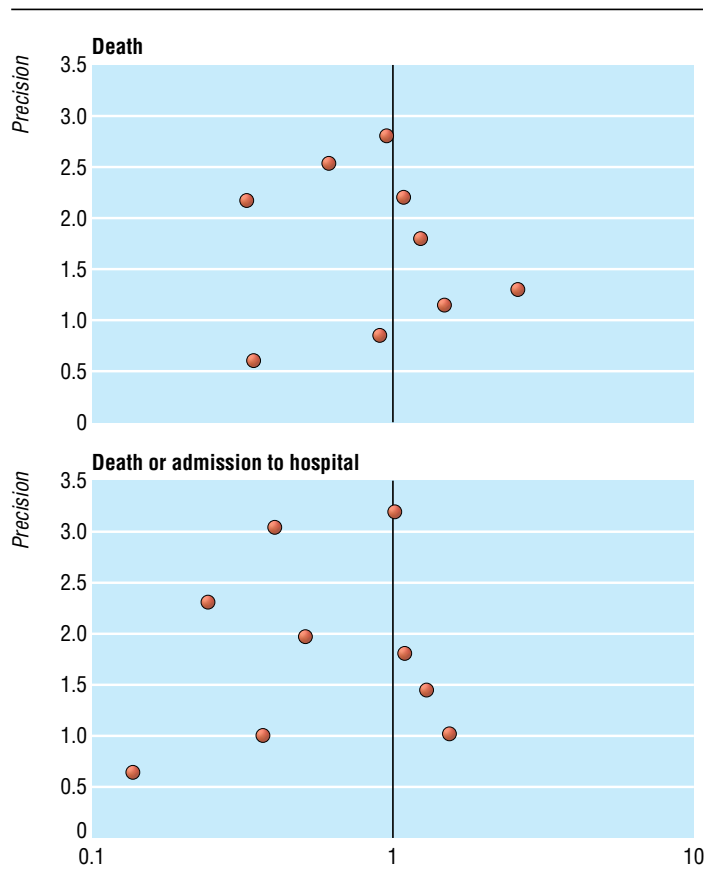

Odds ratio

Fig 2 Funnel plot for detection of publication bias
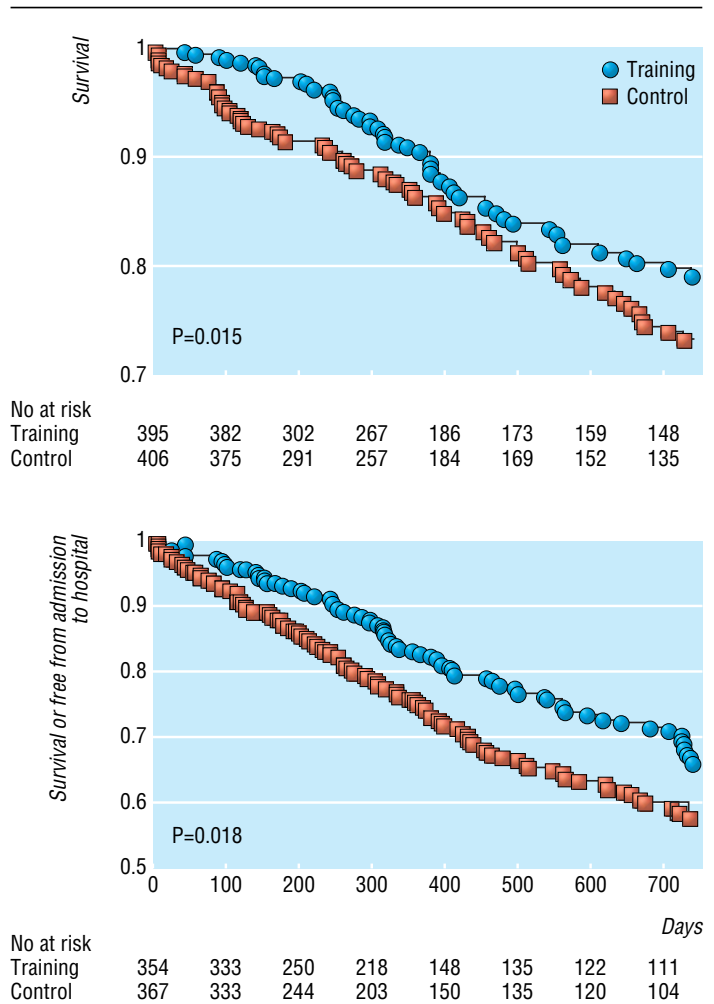

Fig 3 Kaplan-Meier cumulative two year survival (top) and Kaplan-Meier cumulative two year survival or free from admission to hospital (bottom)

between subgroup and treatment effect, and therefore we conclude that there is no evidence that any of the studied subgroups would be less likely to benefit from training.

The mechanism on survival remains unknown. Observational studies in chronic heart failure are essentially unanimous in confirming a strong relation between exercise capacity and survival. ${ }^{17}$ Indeed, observational work in the general healthy population has shown that exercise capacity, even if assessed without metabolic measurements, is a more powerful prognostic indicator than traditional risk factors such as smoking, high blood pressure, blood cholesterol level, and diabetes. ${ }^{18}$

One explanation, applicable to patients with ischaemic causes, is that exercise training improves myocardial perfusion by alleviating endothelial dysfunction and therefore dilating coronary vessels and by stimulating new vessel formation by way of intermittent ischaemia. ${ }^{19} 20$ Ventricular remodelling has been shown to be attenuated by exercise training. ${ }^{11}$

Regardless of cause, there are important neurohormonal and musculoskeletal abnormalities in heart failure. Exercise training may reduce adrenergic tone and increase vagal tone, as suggested by an assessment of variability in heart rate. ${ }^{1}$ In dogs, exercise training raises the ventricular fibrillation threshold. ${ }^{21}$ Skeletal muscle dysfunction and wasting may also respond to exercise training. ${ }^{3}$

Even when the amount of time spent exercising as part of a programme is small, supervised and encouraged exercise is likely to lead to a more active lifestyle, so that the effective "dose" of exercise may be considerably greater than that directly prescribed. Arguably, this contrasts with pharmacotherapy.

\section{Study limitations}

One trial that met all the validity criteria was not included because its raw data could not be obtained. ${ }^{22}$ This was a small trial (12 cases, 13 controls), and its results were of a net benefit of exercise training in exercise tolerance and quality of life. It is unlikely that the principal findings of our meta-analysis would have been altered if the raw data had been available.

Exercise training can necessarily only be trialled in open design studies, and it is important to consider the possibility that there may have been more vigorous prognostic pharmacotherapy in one arm than in the other. At baseline there was no significant difference in treatment pattern between groups. To assess the plausibility of changes in medical therapy as a cause for the reduction in mortality, we asked all the investigators about changes in drugs during the trial. Investigators in six of the nine trials, covering two thirds of the patients, were able to provide information. They stated that there was no change in angiotensin converting enzyme inhibitor, $\beta$ blocker, or antialdosterone therapies during the trial period. As is normal clinical practice, however, patients were allowed to vary their dosage of loop diuretic, but comprehensive data on this are not available.

Since the primary end point was death from any cause (selected to minimise potential for observer classification bias) and there was no evidence of differences in prognostically effective drugs, it seems likely that there is a genuine beneficial effect and that it arises from the exercise training component of the active treatment arm.

Contributors: Members of the Exercise Training Meta Analysis of Trials in Chronic Heart Failure patients (ExTraMATCH) Collaborative are: (a) coordinating committee and writing committee, M F Piepoli, C Davos, D P Francis, and A J S Coats (Cardiac Medicine, Royal Brompton Hospital, Imperial College of Science Technology and Medicine, London); (b) principal investigators, R Belardinelli, A Purcaro (Cardiology Division, Lancisi Institute, Ancona, Italy); P Dubach, J Myers (Cardiology Department, Kantonsspital, Chur, Switzerland); P Giannuzzi, P L Temporelli (Fondazione Salvatore Maugeri, IRCCS, Istituto Scientifico di Veruno, Novara, Italy); R Hambrecht, A Linke (Herzzentrum, Universität Leipzig, Leipzig, Germany); K Kiilavuori, H Leinonen (Division of Cardiology, Central Hospital, Helsinki University, Finland); R S McKelvie, K K Teo (Hamilton Health Sciences, McMaster University, Hamilton, Ontario, Canada); M Volterrani, A Giordano (Fondazione Salvatore Maugeri, IRCCS, Centro Medico di Gussago, Brescia, Italy); R P Wielenga, M R P Baselier (Amphia Hospital, Breda, Netherlands); R Willenheimer, E Rydberg (Department of Cardiology, Uni- 


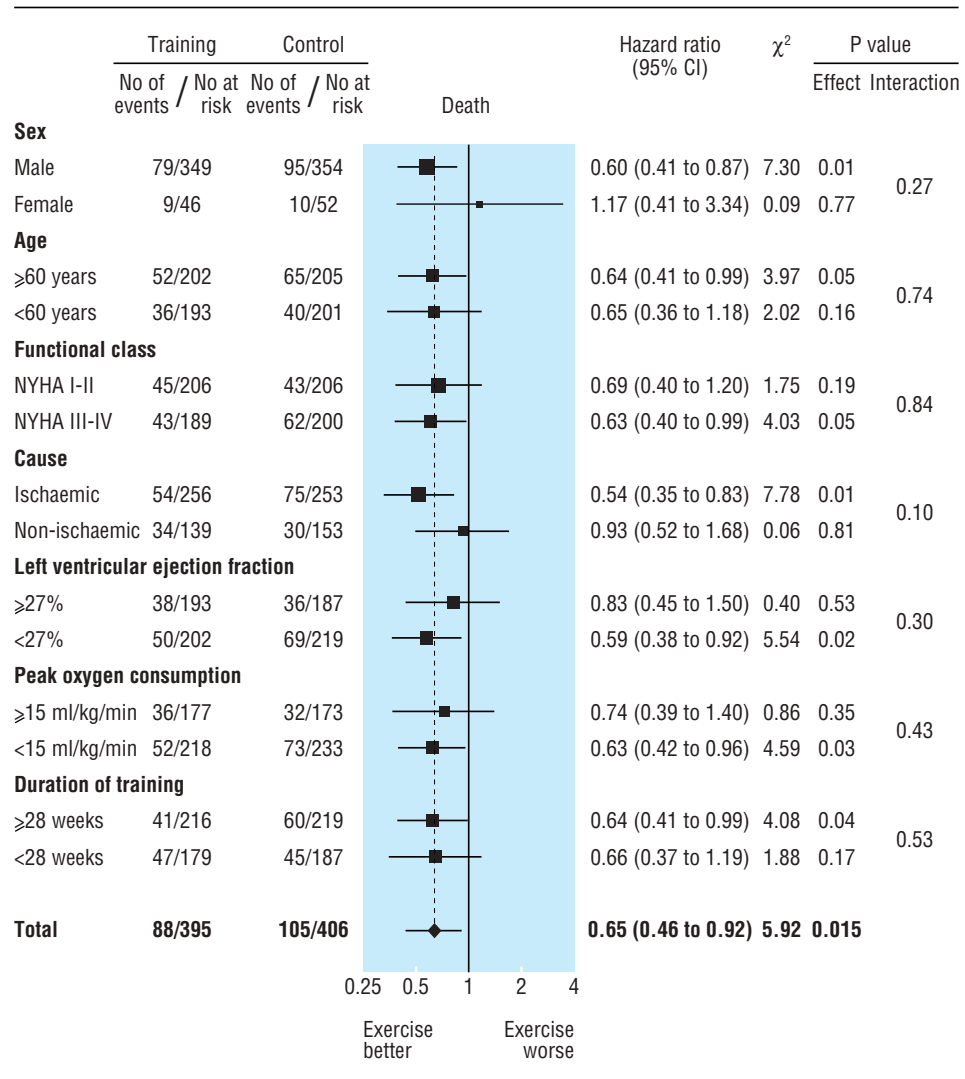

Fig 4 Effect of exercise training on death

versity Hospital, Malmö, Sweden); and (c) other contributors, S Adamopoulos (Cardiology Department, Onassis Cardiac Surgery Centre, Athens, Greece); K Dickestein (Cardiology Division, Central Hospital in Rogaland, Stavanger, Norway); A Gordon (Department of Cardiology, Karolinska Institute, Huddinge University Hospital, Stockholm, Sweden); J B Kostis (Medicine Department UMDNJ Robert Wood Institute, Johnson Medical School, New Brunswick, NJ, USA); P Sellier (Service de Readaptation Cardiaque, Hopital Broussais, Paris, France) and J Toman (First Medical Department, Masaryk University, Brno, Czech Republic). M F Piepoli, C Davos, and A J S Coats designed the study, searched the literature, scrutinised references, checked for consistency and completeness, retrieved data, consulted with the principal investigators. M F Piepoli, C Davos, D P Francis, and A J S Coats analysed the data, undertook the statistical testing, and prepared the manuscript. They will act as guarantors for the paper. The principal investigators who were consulted, contributed data and revised and approved the manuscript. The other contributors who were consulted, contributed data that did not fulfil inclusion criteria for the analysis.

Funding: This work was supported by a grant from the Royal Brompton and Harefield NHS Trust Clinical Research Committee (No 2000CS022B). Conflict of interest: None declared.

Ethical approval: Not required.

1 European Heart Failure Training Group. Experience from controlled trials of physical training in chronic heart failure. Eur Heart J 1998;19:466-75.

2 McKelvie RS, Teo KK, Roberts R, McCartney N, Humen D, Montague T, et al. Effects of McKelvie RS, Teo KK, Roberts R, McCartney N, Humen D, Montague T, et al. Effects of
exercise training in patients with heart failure: the Exercise Rehabilitation Trial (EXERT). Am Heart J 2002;144:23-30.

3 Hambrecht R, Niebauer J, Fiehn E, Kalberer B, Offner B, Hauer K, et al. Physical training in patients with stable chronic heart failure: effects on cardiorespiratory fitness and ultrastructural abnormalities of leg muscles. J Am Coll Cardiol 1995;25:1239-49.

4 Belardinelli R, Georgiou D, Cianci D, Purcaro A. Randomized, controlled trial of long term moderate exercise training in chronic heart failure: effects on functional capacity, quality of life, and clinical outcome. Circulation 1999;99:1173-82.

5 Stewart LA, Parmar MKB. Meta-analysis of the literature of individual patient data: is there a difference? Lancet 1993;341:418-22.

6 Begg CB. Publication bias. In: Cooper H, Hedges LV, eds. The handbook of research synthesis. New York: Russell Sage Foundation, 1994:400-9.

7 Egger M, Davey-Smith G, Schneider M, Minder C. Bias in meta-analysis detected by a simple, graphical test. BMJ 1997;315:629-34.

8 Grambsch P, Therneau T. Proportional hazards tests and diagnostics based on weighted residuals. Biometrika 1994;81:515-26.

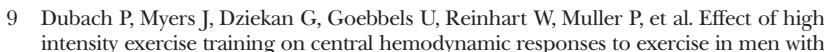
intensity exercise training on central hemodynamic responses to exer

10 Myers J, Wagner D, Schertler T, Beer M, Luchinger R, Klein M, et al. Effects of exercise training on left ventricular volumes and function in patients with nonischemic cardiomyopathy: application of magnetic resonance myocardial tagging. Am Heart $J$ 2002;104:719-25.

11 Giannuzzi P, Temporelli PL, Corra U, Gattone M, Giordano A, Tavazzi L. Attenuation of unfavorable remodeling by exercise training in postinfarction patients with left ventricular dysfunction: results of the Exercise in Left Ventricular Dysfunction (ELVD) trial. Circulation 1997;96:1790-7.

12 Hambrecht R, Gielen S, Linke A, Fiehn E, Yu J, Walther C, et al. Effects of exercise training on left ventricular function and peripheral resistance in patients with chronic heart ing on left ventricular function and peripheral resistance in patient
failure. A randomized trial. J Am Med Assoc 2000:283:3095-101.

13 Kiilavuori K, Naveri H, Salmi T, Harkonen M. The effect of physical training on skeletal muscle in patients with chronic heart failure. Eur J Heart Fail 2000;2:53-63.

14 Zanelli E, Volterrani M, Scalvini S, Musmeci G, Campana M, Zappa C, et al. Multidisciplinary non-pharmachological intervention prevents hospitalization, improves morbidity rates and functional status in patients with congestive heart failure. Eur Heart $J$ 1997;18(abstract suppl):647.

15 Wielenga RP, Huisveld IA, Bol E, Dunselman PH, Erdman RA, Baselier MR, et al. Safety and effects of physical training in chronic heart failure. Results of the chronic heart failure and graded exercise study (CHANGE) Eur Heart J 1999;20:872-9.

16 Willenheimer R, Erhardt L, Cline C, Rydberg E, Israelsson B. Exercise training in heart failure improves quality of life and exercise capacity. Eur Heart J 1998;774-81.

17 Mancini DM, Eisen H, Kussmaul W, Mull R, Edmunds LH Jr, Wilson JR. Value of peak Mancini DM, Eisen H, Kussmaul W, Mull R, Edmunds LH Jr, Wilson JR. Value of peak
exercise oxygen consumption for optimal timing of cardiac transplantation in ambulatory patients with heart failure. Circulation 1991;83:778-86.

18 Myers J, Prakash M, Froelicher V, Partington S, Atwood E. Exercise capacity and mortality among men referred for exercise testing. N Engl J Med 2002;346:793-801.

19 Laughlin MH, McAllister RM. Exercise training-induced coronary vascular adaptation. JAppl Physiol 1992;73:2209-25.

20 White FC, Roth DM, McKirnan D, Carroll SM, Bloor CM. Exercise induced coronary collateral development: a comparison to other models of myocardial angiogenesis. In: Schaper W, Schaper J, eds. Collateral circulation. Norwell, MS: Kluwer Academic; 1993:261-89.

21 Vanoli E, DeFerrari GM, Stramba-Badiale M, Hull SS Jr, Foreman RD, Schwartz PJ Vagal stimulation and prevention of sudden death in conscious dogs with a healed myocardial infarction. Circ Res 1991;68:1471-81.

22 Quittan M, Sturm B, Wiesinger GF, Pacher R, Fialka-Moser V. Quality of life in patients with chronic heart failure: a randomised controlled trial of changes induced by a regular exercise program. Scand J Rehabil Med 1999;31:223-8.

(Accepted 6 November 2003)

doi 10.1136/bmj.37938.645220.EE 


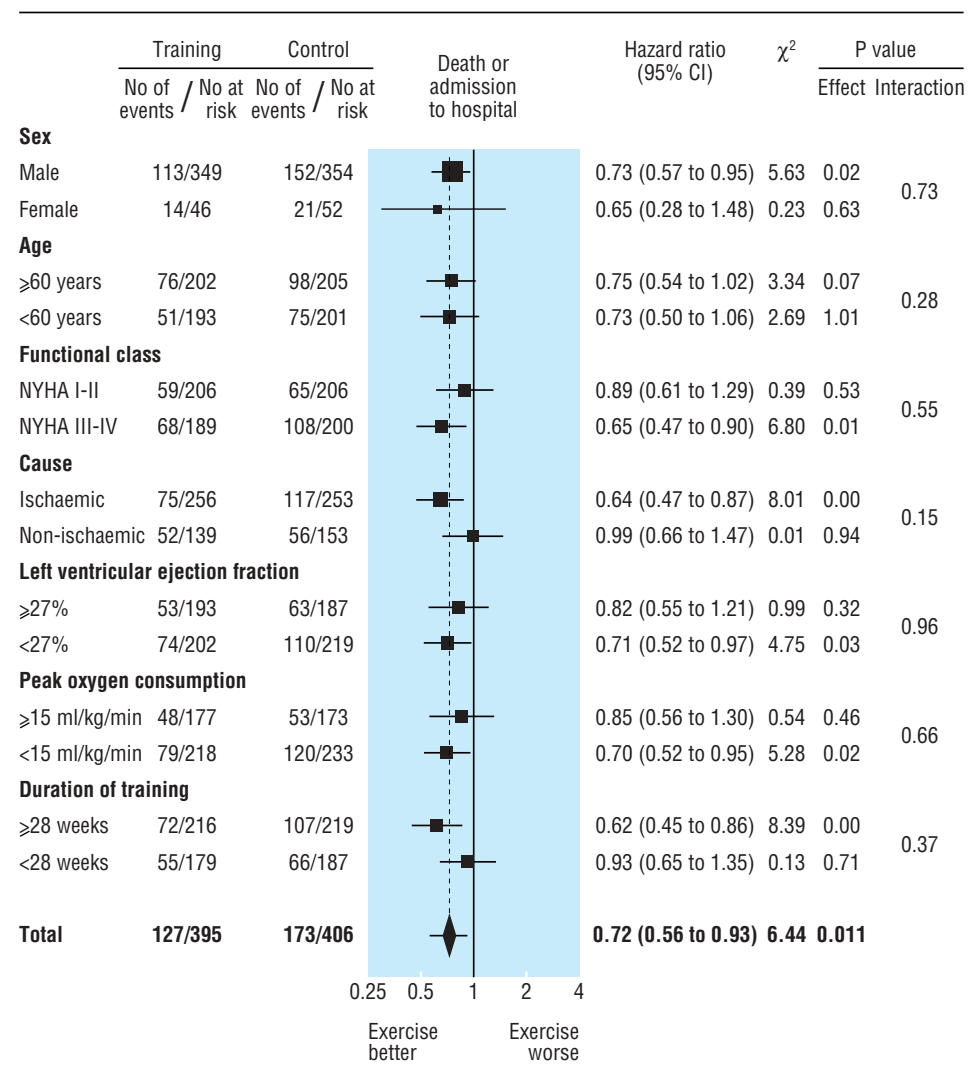

Fig 5 Effect of exercise training on death or admission to hospital

Department of Clinical Cardiology, Imperial College of Science, Technology, and Medicine, Roval Brompton Hospital, London SW3 6NP

ExTraMATCH Collaborative

Correspondence to: M F Piepoli

m.piepoli@imperial.ac.uk 


\section{What is already known on this topic}

Exercise training reduces the debilitating symptoms of chronic heart failure through effects on the cardiovascular and musculoskeletal systems

Exercise training is not widely used because data on its effect on survival are not compelling

\section{What this study adds}

Mortality and admission to hospital are significantly reduced after exercise training in patients with chronic heart failure due to left ventricular systolic dysfunction

This benefit was not restricted to any particular subgroup of patients 